\title{
The European Association for Cancer Education (EACE) 2014 Meeting Report
}

\author{
Darren L. Starmer
}

Published online: 15 June 2014

(C) Springer Science+Business Media New York 2014

It is with great pleasure that I write my first President's report on the back of an extremely successful meeting in Caen, France, in March this year. Having faced our own mortality after two cancelled meetings (one a result of the global financial crisis), the European Association for Cancer Education (EACE) effectively re-launched in 2010. Since that meeting in Enschede, the Netherlands, we have enjoyed fruitful meetings in Nicosia, Cyprus, in 2011, Vienna, Austria, in 2012 and Wroclaw, Poland, in 2013.

Whilst these meetings have been successful, they have relied predominately on a core of EACE and AACE members. One of our biggest challenges has been attracting new members to the association, particularly from countries that have not previously been EACE strongholds. This is particularly problematic in today's economic climate, due to a lack of available funding for (potential) delegates to support their attendance. One of the decisions EACE has made in an attempt to provide some relief is to keep registration costs to a minimum, offer reduced registration fees for delegates from low socio-economic countries and the provision of several travel grants, one of which is reserved for students.

You can imagine our delight when we not only attracted a large number of newcomers to EACE this year but we also discovered that several were from countries that we are trying to engage with. Overall, we had delegates from 11 countries spanning three continents. As always, we enjoyed good representation from AACE, with a healthy mixture of veterans and newcomers to EACE. Student participation was again good, and this is something else that we have been focusing upon building.

D. L. Starmer $(\bowtie)$

School of Medicine, The University of Notre Dame Australia, PO

Box 1225, Fremantle, WA 6959, Australia

e-mail: darren.starmer@nd.edu.au
The meeting provided a well-balanced mix of education, networking and cultural immersion. We had presentations on a variety of educational issues spanning the cancer care continuum from a multitude of multidisciplinary professions. Several presentations were given by first-time presenters, many of whom spoke English as a second (or third) language, and the quality of these presentations was excellent. In fact, they were so good that we were unable to decide on a winner for the Ullabeth Sätterlund Larsson Award for First Time Presenters, so we awarded two as follows: Tamara Rumpold, a psychology student from Vienna, and Penelope Edwards, a junior doctor from the Isle of Wight. The Annie Bosch Memorial Poster Prize went to Marion Sassier, a pharmacist from Caen. The Milly Haagedorn Lecture was presented by Rasoslaw Tarkowski, who gave a very engaging talk about his involvement with a scientific society for medical students in Poland. The manuscript that underpinned his lecture can be found in the March issue of this journal [1]. The abstract book for this meeting is available online [2], and I would encourage you to peruse the abstracts. This is one means through which you can identify and communicate with other cancer educators with similar interests and expand your network.

Successful meetings do not just happen, and we owe a debt of gratitude to our local organiser, Jean-Francois Heron and his staff from the Centre Francois Baclesse, for all their hard work and attention to detail. Personally, I would also like to thank our board members and in particular, our immediate past presidents (Graham Dark and Joy Notter), whose vision and guidance steered the association from what some considered to be an untenable position to see it emerge, once again, as a healthy and vibrant association.

On behalf of the EACE board, I invite you to join us for our 2015 Annual Meeting in Heidelberg, Germany, April 15-17. Information about this meeting will be available soon on our web site, www.eaceonline.com. 


\section{References}

1. Tarkowski R, Kornafel J (2014) Students' Scientific Society-how to inspire students and help them to become oncologists? A tutor's perspective. J Cancer Educ 29(1):11-3
2. The European Association for Cancer Education. European Association for Cancer Education 27th Annual Scientific Meeting Programme and Abstract Booklet. Retrieved from: http://www.eaceonline.com/?page_id=72 Last accessed May 28 2014 